\title{
Clinicopathological Study of Associated Lesions in Benign Prostatic Hyperplasia and Prostatic Adenocarcinoma in Surgical Biopsy Specimens
}

\author{
Sheetal Arora ${ }^{1}$, Deepshikha Rana ${ }^{1 *}$, J.S Dhupia ${ }^{1}$ and Charanjeet Ahluwalia ${ }^{2}$ \\ ${ }^{1}$ Dept. of Patholog,ESIC Medical College, Faridabad, Haryana(India) \\ ${ }^{2}$ Dept. of Pathology, Safderjang hospital, New Delhi(India)
}

\begin{abstract}
Introduction: The susceptibility to infections in thalassemia arises from a large spectrum of immunological abnormalities and from the exposure to infectious agents by allogenic blood transfusions. Increased hepatic iron may potentiate progression towards liver fibrosis in chronic $\mathrm{HCV}$ infection and may contribute to poor response to therapy

Objective: (1)To determine the prevalence of hepatitis B and hepatitis C in thalassemic paediatric patients. (2) To determine the relationship between elevated liver enzymes with serum ferritin and viral hepatitis in thalassemia.

Method: Sera was obtained from 100 thalassemia children and was processed for anti-HCV and HBsAg, serum ferritin,ALT/SGPT \& AST/SGOT

Results: 100 subjects were evaluated. Eight subjects (8\%) were HBsAg positive and six (75\%)received more than 100 blood transfusions. Out of these eight subjects with, seven had raised SGOT, \& six had raised SGPT. Four subjects were positive for hepatitis C \& all of them $(100 \%)$ received more than hundred blood transfusions.All four HCV subjects had raised SGOT \& SGPT ( $\mathrm{p}=0.037)$.SGOT was raised in 68\% subjects and $47(69 \%)$ had more than 100 blood transfusions ( $\mathrm{p}=0.002)$. SGPT was raised in $49 \%$ subjects and $37(75.5 \%)$ had more than 100 blood transfusions. $86 \%$ subjects had serum ferritin in range of $1000-2000 \mathrm{ng} / \mathrm{ml} \& 14 \%$ had serum ferritin $<1000 \mathrm{ng} / \mathrm{ml}$.Serum ferritin showed strong correlation with SGOT \& SGPT $(\mathrm{p}=0.036 \& \mathrm{p}=0.002)$.

Conclusions: Prevalence of hepatitis B in Thalassemic's in our study was $8 \%$ while hepatitis B in general population is $4.35 \%$. Hepatitis C was $4 \%$ in our study while that in children in general population is $0.31 \%$. Serum ferritin showed significant correlation with SGOT \& SGPT. This finding suggests that iron overload is one of the major causes of abnormal liver function in subjects with thalassemia.So the treatment of hepatitis as well as iron overload should be done to prevent progression to liver disease.
\end{abstract}

\section{Keywords: Hepatitis, Ferritin, SGOT,SGPT}

\section{Introduction}

Thalassemia is among the most common and diverse genetic disorders, and nearly $7 \%$ of the world carry a hemoglobinopathy. ${ }^{[1]}$ The burdenis in many regions is of such aisepimagnitude that it represents a major public health which is the main growth andisepsuppresses ineffective erythropoiesis. [3] Iron iron chelating agents are not used properly. [4] Even in the sépiabsence of transfusion, the accelerated rate of gut, resulting in a chronic state of iron overload. [5] As patients with thalassemia commonly receive transfusions, they are exposed to transfusion associated infections, where hepatitis $\mathrm{B}$ and hepatitis $\mathrm{C}$ are the most common infections detected. Interrelationship between iron overload, HCV infection and liver injury is still controversial. Multicentre cross-sectional studies have reported that the development and the severity of liver injury are strongly related to the extent of liver iron overload and to the presence of chronic HCV infection. ${ }^{[6,7]}$ Long-term observation of thalassemics who had undergone bone marrow transplantation(BMT) showed that severe iron overload and chronic HCV infection were independent risk factors for liver injury. ${ }^{[8]}$ Hepatitis virus $\mathrm{C}$ infection is the main risk factor for liver injury in transfusion-dependent thalassemics. ${ }^{\text {[9] Dimitrios }}$ et al (2013) ${ }^{[10]}$ on the other hand suggested that in the late stages of liver disease in BTM patients, iron overload may be the critical determinant, since fibrosis is related to the minimal haemosiderosis, independently of HCV history. Injury to the liver, whether acute or chronic, eventually results in an increase in serum concentrations of Alanine transaminase (ALT) and Aspartate transaminase (AST). ${ }^{[1]}$ The susceptibility to infections in thalassemia arises both from a large spectrum of immunological abnormalities and 
from the exposure to infectious agents by allogenic blood itself, i.e. all those changes inherent to the pathological process which can interfere with the immune systems; Iron overload, transfusion therapy and the role of the spleen. Though regular blood transfusion improves the overall survival of patients with beta thalassemia; it carries a definite risk of infection with blood-borne viruses. Although the risk of infection is decreased due to routine screening and vaccination ${ }^{(12)}$, it may occasionally be transmitted through transfusion of blood units that are hepatitis $\mathrm{B}$ surface antigen (HBsAg) negative but HBV DNA positive or due to seronegative window period and are missed by ELISA. ${ }^{[13,14]} \mathrm{HCV}$ infection was widely diffused among thalassemia patients who had been transfused before 1989 when the virus was identified and before a systematic screening of blood units was performed.The residual risk of transfusion transmitted infections associated with the window period donations is extremely low in industrialized countries, especially after the introduction of nucleic acid amplification testing (NAT) technology to screen blood donations ,but it remains significant where the prevalence of infection in the population is high. The aim of this study to determine the relationship between liver enzymes with serum iron status and HCV, HBV infection in thalassemic patients and to throw light on the percentage of $\mathrm{HBV}$ and $\mathrm{HCV}$ in the studied patients.

\section{Methods}

This study was undertaken in Department of Pathology in a tertiary care Hospital for a period of two years. Thalassemia children were diagnosed by haemoglobin electrophoresis in Haematology department and were enrolled for the study after obtaining written / informed consent of parent / guardian of the child. Detailed clinical history regarding frequency of blood transfusions in both parents and child \& other relevant history was recorded. After clinical examination of child, blood sample (about $4 \mathrm{ml}$ ) was collected by venepuncture\& processed as plain vial (serological investigations): HBsAg, Anti HCV (IgM), Serum Ferritin, AST \& ALT STPBAg was solid phase enzyme linked immunosorbent assay (ELISA) based on the "direct sandwich" principle.

HCV (IgM) was based on non-competitive "sandwich" ELISA.ALT and AST were obtained from automated analyzer (Hitachi). This method uses a rate method and a factor calculation.

Sample Size: In the present study, 100 cases of thalassemia were evaluated. There were 90 cases $(90 \%)$ of $\beta$ - thalassemia, 2 cases ( $2 \%$ ) of $\alpha$-thalassemia, $2(2 \%)$ were double heterozygous for $\mathrm{HbE}-\beta$ thalassemia trait, $4(4 \%)$ were $\mathrm{HbD}$ Punjab and $2(2 \%)$ were $\mathrm{HbS} \beta$ thalassemia
trait:SEpististical Analysis: in EPI-INFO \& SPSS statistical softwares. The primary outcomes of interest in relation to thalassemic infections were $\mathrm{HBsAg}, \mathrm{HCV}$ which were related to SGOT,SGPT and number of blood transfusions. The relationship of serum ferritin with SGOT, SGPT was also analyzed. The statistical tests employed included Chi-Square test, Fischer's exact test, student ' $t$ ' test, Pearson's correlation coefficient, univariate\& multiple regression analysis, univariate\& multiple logistic regression analysis.p-value $<0.05$ was considered to denote statistical significance. Non parametric data was analysed using Mann Whitney test. Binomial test was done for test of proportion.

Inclusion Criteria: Children between 6 months to 12 years, in whom thalassemia was confirmed by haemoglobin electrophoresis.

Exclusion criteria1. Children more than 12 year's age were excluded.2. Children on anti-tubercular treatment.ssepi3. Children suffering from other haemolyticanaemia.

\section{Results}

In the present study, mean age was 10.05 ( $\mathrm{SD} \pm 2.580)$. The majority (56\%) of the cases were between 11 and 12 years of age and $39 \%$ were between 6 and 10 years of age and remaining $5 \%$ were between 1 to 5 years of age. The study included $57 \%$ male and $43 \%$ female subjects. Eight patients were positive for $\mathrm{HBs} \mathrm{Ag}(8 \%)$.

Six patients $(75 \%)$ of these eight patients received more than 100 blood transfusions. Seven patients of HBs Ag positivity $(87.5 \%)$ had raised SGOT and six patients of HBsAg positivity (75\%) had raised SGPT. Four patients were positive for Hepatitis C (IgM) (4\%). All the four HCV patients $(100 \%)$ had received more than 100 blood transfusions. All the four HCV positive patients had raised SGOT and SGPT. SGOT was raised in $68 \%$ patients. SGPT was raised in $49 \%$ patients. Serum ferritin was raised $(1000-2000 \mathrm{ng} / \mathrm{ml})$ in $86 \%$ patients. Serum ferritin showed significant correlation with SGOT $(\mathrm{p}=0.036)$ and SGPT $(\mathrm{p}=0.002)$.

\section{Discussion}

Management of patients suffering with $\beta$ thalassemia is based on adequate and safe blood transfusions and receiving regular ironchelation therapy, all of which improve the quality of life and survival of patients. ${ }^{[15]}$ This study was designed to determine the prevalence and incidence of transfusion transmitted infections in multiply transfused thalassemia patients during the study period. Apart from hepatitis, our study has shown that iron burden affects liver function in thalassemic patients. Patients with thalassemia major require repeated transfusions of blood exposing them 
Table 1: Mean, median and standard deviation of various variables.

\begin{tabular}{|l|c|c|c|c|}
\hline & AGE & $\begin{array}{c}\text { NUMBER OF BLOOD } \\
\text { TRANSFUSION }\end{array}$ & SGOT \\
\hline $\mathrm{N}$ & 100 & 100 & 100 & 100 \\
\hline MINIMUM & 1 & 6 & 4 & 10 \\
\hline MAXIMUM & 12 & 360 & 244 & 193 \\
\hline RANGE & 11 & 354 & 240 & 57.91 \\
\hline MEAN & 10.05 & 159.88 & 39.680 & 41.454 \\
\hline STANDARD DEVIATION & 2.580 & 80.309 & 48.0 & 37.50 \\
\hline MEDIAN & 11.0 & 151.0 & 3.968 & 4.145 \\
\hline STD. ERROR OF MEAN & 0.258 & 8.031 & & \\
\hline
\end{tabular}

Table 2: Relationship between Hepatitis $\mathrm{C}$ virus and SGOT.

\begin{tabular}{|l|c|c|c|c|}
\hline & & SGOT<37 & SGOT>37 ELEVATED & TOTAL \\
\hline \multirow{2}{*}{ IgM HCV POSITIVE } & COUNT & 0 & 4 & 4 \\
\cline { 2 - 5 } & $\%$ WITHIN IgM HCV & 0 & $100 \%$ & $100 \%$ \\
\hline \multirow{2}{*}{ IgM HCV NEGATIVE } & COUNT & 32 & 64 & 96 \\
\cline { 2 - 5 } & $\%$ WITHIN IgM HCV & $33.3 \%$ & $68 \%$ & $100 \%$ \\
\hline \multirow{2}{*}{ TOTAL } & COUNT & 32 & $68 \%$ & 100 \\
\cline { 2 - 5 } & $\%$ WITHIN IgM HCV & $32 \%$ & $100 \%$ \\
\hline
\end{tabular}

Table 3: Relationship between Hepatitis C virus and SGPT.

\begin{tabular}{|l|c|c|c|c|}
\hline & & SGPT<40 & SGPT>40 ELEVATED & TOTAL \\
\hline \multirow{2}{*}{ IgM HCV POSITIVE } & COUNT & 0 & 4 & 4 \\
\cline { 2 - 5 } & $\%$ WITHIN IgM HCV & 0 & $100 \%$ & $100 \%$ \\
\hline \multirow{2}{*}{ IgM HCV NEGATIVE } & COUNT & 51 & 45 & 96 \\
\cline { 2 - 5 } & $\%$ WITHIN IgM HCV & $51.1 \%$ & $46.9 \%$ & $100 \%$ \\
\hline \multirow{2}{*}{ TOTAL } & COUNT & 51 & 49 & 100 \\
\cline { 2 - 5 } & $\%$ WITHIN IgM HCV & $51 \%$ & $49 \%$ & $100 \%$ \\
\hline
\end{tabular}

Table 4: Relationship between Serum Ferritin and SGOT

\begin{tabular}{|c|c|c|c|c|}
\hline & & SGOT<37 & SGOT>37 ELEVATED & TOTAL \\
\hline \multirow{2}{*}{$\begin{array}{l}\text { SERUM FERRITIN< } \\
1000 \mathrm{ng} / \mathrm{ml}\end{array}$} & COUNT & 6 & 8 & 14 \\
\hline & \% WITHIN SERUM FERRITIN & $42.9 \%$ & $57.1 \%$ & $100 \%$ \\
\hline \multirow{2}{*}{$\begin{array}{l}\text { SERUM FERRITIN } \\
1000-2000 \mathrm{ng} / \mathrm{ml}\end{array}$} & COUNT & 26 & 60 & 86 \\
\hline & \% WITHIN SERUM FERRITIN & $30.2 \%$ & $69.8 \%$ & $100 \%$ \\
\hline \multirow{2}{*}{ TOTAL } & COUNT & 32 & 68 & 100 \\
\hline & \% WITHIN SERUM FERRITIN & $32 \%$ & $68 \%$ & $100 \%$ \\
\hline
\end{tabular}

Table 5: Relationship between Serum Ferritin and SGPT

\begin{tabular}{|c|c|c|c|c|}
\hline & & SGPT $<40$ & SGPT>40 ELEVATED & TOTAL \\
\hline \multirow{2}{*}{$\begin{array}{l}\text { SERUM FERRITIN< } \\
1000 \mathrm{ng} / \mathrm{ml}\end{array}$} & COUNT & 7 & 7 & 14 \\
\hline & \% WITHIN SERUM FERRITIN & $50.0 \%$ & $50.0 \%$ & $100 \%$ \\
\hline \multirow{2}{*}{$\begin{array}{l}\text { SERUM FERRITIN } \\
1000-2000 \mathrm{ng} / \mathrm{ml}\end{array}$} & COUNT & 44 & 42 & 86 \\
\hline & $\%$ WITHIN SERUM FERRITIN & $51.2 \%$ & $48.8 \%$ & $100 \%$ \\
\hline \multirow{2}{*}{ TOTAL } & COUNT & 51 & 49 & 100 \\
\hline & \% WITHIN SERUM FERRITIN & $51 \%$ & $49 \%$ & $100 \%$ \\
\hline
\end{tabular}


to the risk of TransfusionTransmitted Diseases (TTDs). The probability of acquiring TTDs is related to the probability of being exposed to the infected units of blood. This probability depends on the prevalence of carriers among the blood donors in the population and the number of units transfused. Thus, the infection rate of TTDs increase with age in subsequent years. In our study, the prevalence of HBsAg was $8 \%$ in thalassemic Paediatric patients. A similar study by Singh Pradhan et al ${ }^{[16]}$ also showed 5.7\% HBsAg positivity in thalassemic children whereas the prevalence of hepatitis B in general population is $4.35 \%{ }^{[17]}$ showing that thalassemic paediatric patients have higher prevalence in comparison to general population. In order to find the cause of increased prevalence of Hepatitis B in thalassemics, we correlated the Hepatitis B viral infection with the number of blood transfusions. It was found that out of eight hepatitis B positive patients,six (75\%)had received more than 100 blood transfusions. Though it was not statistically significant but it clearly reveals that increase in the number of blood transfusion is an important factor leading to the increase in the prevalence of hepatitis $\mathrm{B}$ in these patients. Mansour et al ${ }^{[18]}$ also found that that number of blood transfusions was directly proportional to hepatitis B infection.

This present study shows that the rapid tests and ELISA are inferior compared to Nucleic Acid Amplification Test (NAT). Our finding is consistent with a previous report which indicated that rapid test and ELISA have not shown any promising results compared to NAT and hence should not be recommended in transfusion centre solely for screening blood donors for Hepatitis virus. ${ }^{[19]}$ Prevention of transfusion transmitted hepatitis B virus (HBV)

continues to rely on serological screening of blood donors using rapid test kits and ELISA rather than the progressively more sensitive NAT technique employed in most developed countries to detect chronic carriers including those with low-level viremia who lack

detectable HBsAg. ${ }^{[20]}$ There is need for the combination of HBsAg rapid test along with ELISA and NAT. Cost effectiveness has erroneously been a reason put forward why developing countries cannot incorporate both ELISA and HBV DNA detection into HBV

screening of donors. It must however be noted that the cost of long-term treatment of a patient who contracts HBV from blood transfusion far outweigh the cost of testing donor units for HBV using ELISA and NAT. An unsafe blood transfusion is very costly from both human and economic points of view. Morbidity and mortality resulting from the transfusion of infected blood have far-reaching consequences, not only for the recipients themselves, but also for their families, their communities and the wider society. ${ }^{[21]}$

Both NAT and ELISA test showed a better performance (higher positive predictive value, higher negative predictive value and fewer cases of false negatives) value. Positive Predictive Value (PPV) is the ability of an assay to identify actual infected individuals among all persons giving a positive result with the kit being used. Negative predictive value is the ability of an assay to identify correctly the real non-infected individuals among persons giving a negative result with the kit being used. A good assay for an infectious agent like HBV from a diagnostic point of view is one with a high positive predictive value and less cases of false negatives. ${ }^{[22]}$ However, ELISA and most recently HBV nucleic acid testing (NAT) was recently developed to detect HBsAg-negative blood units donated during early acute phase of infection. ${ }^{[23]}$ The major challenge with NAT is that it is more expensive, require use of instrumentation, time consuming and requires trained personnel. Nucleic acid amplification testing (NAT) is becoming the gold standard for blood donor screening in the developed world particularly because of its ability to reduce the risk of rapid kit and enzyme immunoassay (EIA)-negative, NATreactive donations from entering the blood donor pool. ${ }^{\text {[24] }}$ Previous report indicates that implementation of NAT will provide a significant increment in safety relative to serological screening alone. ${ }^{[25]}$

It is well documented that some commercial ELISA kits could detect the wild type but not the mutant viruses ${ }^{[13]}$ or else it could be due to seronegative window period. ${ }^{[14]}$ There are individuals who have occult hepatitis infection (OBI). Individuals with OBIs are defined as those in whom viral DNA is detected in liver or blood by nested PCR or real time PCR but in whom HBsAg is undetectable in serum by current commercial HBsAg assays. ${ }^{[26]}$ Thus, in order to reduce the transmission of virus through blood transfusion, screening should be done through NAT (Nucleic Acid Amplification Test). Blood transfusion to these thalassemic patients is done after stringent donor selection and after screening tests.But even after this, $8 \%$ were positive for HBsAg (having no other source of infection).It appears that these thalassemics are exposed to viral infection during the blood transfusions.

As hepatitis $\mathrm{C}$ is known to be transmitted by blood, so we carried out the investigation of hepatitis $\mathrm{C}$ in these patients. The prevalence of hepatitis $\mathrm{C}$ is $0.31 \%$ in general population while in our study, prevalence of hepatitis $\mathrm{C}$ in thalassemic patients was $4 \%$. ${ }^{[27]}$ Again it was not statistically significant but is quite high in comparison to general population. This also emphasizes to search for the 
cause of this high prevalence in these patients. As there was no other source of infection in these paediatric patients, multiple transfusions appear to be the main risk factor. We found that all the four hepatitis $\mathrm{C}$ positive patients received more than 100 blood transfusions. Ocak S, Kaya et al also found that increase in the number of blood transfusions increases the prevalence of hepatitis $\mathrm{C}$ infection. But the transfusion they received was screened by Elisa technique, again emphasizing the need for more stringent techniques such as Nucleic Acid Amplification (NAT)to be used in blood donors. ${ }^{[28]}$

As these patients receive multiple blood transfusions, they are prone to transfusion transmitted infections along with iron overload. The liver plays a central role in iron homeostasis. In addition to iron released from transfused red cells, an enhanced rate of gastrointestinal iron absorption has been suggested. This excess iron is initially confined to the Kupffer cells but when transfusion requirements produce massive iron overload, spillover to hepatic parenchyma cells quickly occurs, with the risk of late development of fibrosis and cirrhosis. In patients with $\beta$-thalassaemia, in absence of co-factors, the threshold hepatic iron concentration for the development of fibrosis is about $16 \mathrm{mg} / \mathrm{g}$ dry weight liver (Angelucci, 2002). [29] Clinical studies suggest a relationship between hepatic iron concentration and the development of iron-induced hepatotoxicity. The risk of liver fibrosis is highest in patients with HCV infection along with iron overload, i.e, they are at even more prone to liver damage. In order to evaluate this, we correlated hepatitis with liver enzyme parameters and serum ferritin with liver enzyme parameters.

Seven out of eight patients with hepatitis B had raised SGOT $(p=0.218)$, six out of eight patients had raised SGPT $(p=0.125)$. All four HCV patients had raised SGOT $(p=0.161)$ and SGPT $(p=0.037)$. As only SGPT showed significant increase in hepatitis $\mathrm{C}$ patients, the abnormally raised levels of SGOT and SGPT were correlated with serum ferritin (iron overload).

$86 \%$ patients had serum ferritin in range of $1000-2000 \mathrm{ng} /$ $\mathrm{ml}$ and remaining $14 \%$ had serum Ferritin $<1000 \mathrm{ng} / \mathrm{ml}$. Highly significant correlation was found between serum ferritin \& abnormal results of liver function i.e. SGOT $\& \operatorname{SGPT}(\mathrm{p}=0.036 \& \mathrm{p}=0.002)$. Wanachiwanawin et al and Omar et al also showed highly significant correlation between serum ferritin level and levels of SGOT \& SGPT. [30,15] Our findings confirm the hepatic consequences of iron overload in cases of thalassemia. The presence of HCV aggravated the effects of iron overload on certain liver functions eg, SGPT. The influence of iron burden on hepatic dysfunction resulting from $\mathrm{HCV}$ could not be evaluated because of the small number of patients.

This statistically significant positive correlation between serum transaminases and serum ferritin suggests that iron overload is one of the major cause of abnormal liver function in these thalassemia patients. So the treatment of both iron overload and hepatitis, if coexisting in patients with thalassemia, is required to prevent progression to chronic liver disease. Moreover, this iron overload can even lead to poor response to interferon in $\mathrm{HCV}$ positive patient, increasing the need to treat iron overload.

\section{Conclusion}

HBV, HCV infections are prevalent TTIs among multiple blood transfused patients of beta thalassaemia and remain a major health problem for these patients. These results showed that due to screening tests and stringent donor selection, prevalence of hepatitis has significantly reduced, but there is still minor risk for infections in Thalassemia patients. So more stringent techniques such as NAT (Nucleic acid Amplification Technique) should be used in blood donors for further reduction in transmission rate. There was no significant correlation in patients suffering from hepatitis with liver function parameters (SGPT, SGOT). Serum ferritin showed significant correlation with SGOT \& SGPT. This finding suggests that iron overload is one of the major cause of abnormal liver function in patients with Thalassemia. So the treatment of hepatitis as well as iron overload should be done to prevent progression to chronic liver disease.

\section{References}

1. Luz A, Sans M, Kimura E, Albuquerque D, et al. Thalassemia, HbS, and $\beta$-globin gene cluster haplotypes two Afro-Uruguayan sub-populations from northern southern Uruguay. Genet Mol Biol. 2006; 29: 595-600.

2. Karimi M, Ghavanini AA, and Kadiva MR. Regional mappin the Gene frequency of $\beta$-Thalassemia in Fars Province, during 1997-1998. Iran J Med Sci. 2000; 25(3\&4):134-137.

3. Ameli M, Besharati S, Nemati K, Zamani F. Relations between elevated liver enzyme with iron overload and $\mathrm{V}$ hepatitis in thalassemia major patients in Northern Iran. Sa Med J. 2008; 29(11):1611-5.

4. Ardalan FA, Osquei MR, Toosi MN, Irvanloo G. Synergic e of chronic hepatitis $\mathrm{C}$ infection and beta thalassemia $\mathrm{m}$ with marked hepatic iron overload on liver fibrosis: retrospective cross-sectional study. BMC Gastroente 2004; 4:17.

5. Papanikolaou G, Tzilianos M, Christakis JI, Bogdanos D et Hepcidin in iron overload disorders. Blood. 2005; 105: 4103- 4105.

6. Feld J, Lee JY, Locarnini S. New targets and possible new therapeutic approaches in the chemotherapy of chronic hepatitis B. Hepatology. 2003;38(3):545-53. 
7. Khalifa AS, El-Sayed MH, Moustafa AO, Mohammed MM, Rady MS, Salama II. Hepatitis C virus infection in children with hematological diseases: risk factors and reliability of diagnosis assays. Egypt J Pediatr. 2002;19: 293-308. is șpep

8. Omar N, Salama K, Adolf S, El-Saeed GS, et al. Major risk of blood transfusion in hemolytic anemia patients. Blood

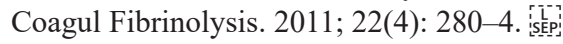

9. El-Faramawy A, El-Rashidy O, Tawfik P, Hussein G. Transfusion Transmitted Hepatitis: Where Do We Stand Now? A One Center Study in Upper Egypt. Hepat Mon. 2012;12(4): 286-291. ichepi

10. Li CK, Chik K, Lam C, To $\mathrm{K}$ et al, Liver disease in transfusion dependent thalassemia major. Arch Dis Child.

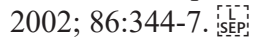

11. Cunningham M, Macklin E, Neufeld E, Cohen AR. Thalassemia Clinical Research Network. Complications of $\beta$ - thalassemia major in North America. Blood. 2004; 104:34-39. SWEP dependent thalassemics: the role of iron overload and chronic hepatitis C. Haematologica. 2008; 93(8):1243-1246.

12. Feld J, Lee JY, Locarnini S. New targets and possible new therapeutic approaches in the chemotherapy of chronic hepatitis B. Hepatology. 2003;38(3):545-53

13. Lin YY, Qiang F, Shun ZM, Jie C, Ming MG ,Hu HZ, Bing CX. Virology Journal 2012,9(82). Pourazar A, Salehi M, Jafarzadeh A, Arababadi M K,Oreizi F,Shariatinezbad. IJI.2005;2(3).

14. 14. Alter $\mathrm{H} \mathrm{J}$. To $\mathrm{C}$ or not to $\mathrm{C}$ :these are the questions. Blood.1995;85:1681-1695.

15. Olivieri NF, Brittenham GM. Ironchelating therapy and the treatment of thalassemia. Blood. 1997;89:739-61.

16. 16. Oamer S, Shahab T, Alam S, Malik A, Afzal K. Age specific prevalence of hepatitis B surface antigen in pediatric population of Aligarh, North India Indian J. Pediatr.2004;71 (11) :965-17.

17. Yuan Q, Qu SH, Chen CR, Ge SX, Pei B, Chen QR, Yan Q, Lin Y C, Ni HY, Huang CH et al. Journal of Clinical Microbiology 2010,48 (2)357-362.

18. Torane VP, Shastri JS (2008) Comparison of ELISA and rapid screening tests for the diagnosis of HIV, hepatitis B and hepatitis $\mathrm{C}$ among healthy blood donors in a tertiary care hospital in Mumbai. Indian J Med Microbiol 26: 284-285.
19. Busch MP (2004) Should HBV DNA NAT replace HBsAg and/or anti-HBc screening of blood donors? Transfus Clin Biol 11: 26-32.

20. Iqbal HS, Solomon S, Murugavel KG, Solomon SS, Balakrishnan P (2005)Evaluation and diagnostic usefulness of domestic and imported enzyme-linked immunosorbent assay for the detection of HIV type 1 antibody inIndia. Clin Diagn Lab Immunol 12: 1425-1428.

21. World Health Organization (WHO) (2007) Status of blood safety in the WHO African Region. Report of the 2004 Survey WHO Regional Officefor Africa, Brazzaville.

22. Kuhns MC, Busch MP (2006) New strategies for blood donor screening for hepatitis Bvirus: nucleic acid testing versus immunoassay methods.Mol Diagn Ther 10: 77-91.

23. Vermeulen M, Lelie N, Sykes W, Crookes R, Swanevelder $\mathrm{J}$ et al. (2009) Impact of individual-donation nucleic acid testing on risk of human immunodeficiency virus, hepatitis $B$ virus, and hepatitis $C$ virus transmission by blood transfusion in South Africa. Transfusion 49:1115-1125.

24. Zhu H, Li G, Lv M, Wu D, Li X (2013) A pilot study on screening blooddonors with individual-donation nucleic acid testing in China. BloodTransfus 23: 1-8.

25. Chowdhury A, Santra A, Chaudhuri S, Dhali GK, Chaudhuri S, Maity SG, Naik TN, Bhattacharya SK, Mazumder DN. Hepatitis $\mathrm{C}$ virus infection in the general population: a community-based study in West Bengal, India.Hepatol 2003; 37:802-09.

26. Ocak S, Kaya H, Cetin M, Gali E, Ozturk M. Seroprevalence of Hepatitis B \&Hepatitis C in patients with thalassemia and sickle cell anemia in a long term follow up. Archives of medical Research 2006;37(7);895-98. [i

27. WanachiwanawinW, Luengrojanakul P, Sirangkapracha P et al .Prevalence \& Clinical significance of Hepatitis $C$ virus infection in Thai patients with Thalassemia. Int.JHematol 2003;78(4):374-78. SE-P

28. Angelucci E, Muretto P, Nicolucci A, et al. Effects of iron overload and $\mathrm{HCV}$ positivity in determining progression of liver fibrosis in thalassaemia following bone marrow transplantation. Blood. 2002;100:17-21.

29. Omar, Naglaa, Salama, Khaleda, Adolf, Sonyab, El-Saeed, Gamila SM, Ghaffar A, Nazwad, Ezzat, Nivind. Major risk of blood transfusion in hemolytic anaemia patients. Blood Coagulation \& Fibrinolysis.2011;22(4)280-284.

*Corresponding author:

Dr. Deepshikha Rana, MD (Pathology),Tutor,Dept. of Pathology,ESIC Medical College, Faridabad, Haryana(India)

Phone: +91 8527091742

Email: ranadeepshikha@yahoo.com

Financial or other Competing Interests: None. 